\title{
Lifecycle Environmental Impact of High-Speed Rail System in the Houston-Dallas I-45 Corridor
}

\author{
Jesuina Chipindula ${ }^{1}$,Venkata Botlaguduru ${ }^{1}$, Doeun Choe $^{2}$, and Raghava Kommalapati ${ }^{1,2, *}$ \\ ${ }^{1}$ Center for Energy \& Environmental Sustainability, Prairie View A\&M University, Prairie View, TX 77446 \\ ${ }^{2}$ Department of Civil and Environmental Engineering, Prairie View A\&M University, Prairie View, TX 77446
}

\begin{abstract}
Texas has the highest rate of the U.S energy related greenhouse gas (GHG) emissions, and transportation is one of the major contributors. The Houston-Dallas corridor is the busiest routes in Texas. Recently, the development of an intercity High-Speed Rail System (HSR) with Shinkansen N700 series trains has commenced. This study builds the life cycle inventories for vehicles and infrastructure in the HSR system, and conducts a preliminary environmental life cycle assessment. Results indicate that over the design life of the HSR system the total GHG emissions from the vehicle life-time are $9.695 \mathrm{kgCO}_{2} \mathrm{eq} / \mathrm{VKT}$, and fossil-fuel usage during vehicle operation is the primary contributor $(97 \%)$. For the infrastructure, total life-time GHG emissions are $239 \mathrm{kgCO}_{2} \mathrm{eq} / \mathrm{VKT}$, out of which, $94 \%$ are from the construction stage. Infrastructure is the dominant contributor to end-point impacts in human health category, with $58 \%$ of total impact across all damage categories.
\end{abstract}

\section{Introduction}

Global environmental degradation represents one of the world's critical issues and transportation is one of the sectors with a continuous growth in emissions and pollutants. In U.S, transportation represents the second biggest contributor to global warming and resource depletion, and Texas contributes with the highest emissions values in the entire country [1]. The Environmental Protection Agency (EPA) 2014 National Emission Inventory shows that vehicles (on and off road) contributed with $67 \%$ of nitrogen oxide (NOx) emissions, and $23 \%$ of volatile organic (VOC) emissions in the Greater Houston Area which is directly linked to increase population and the use of medium and heavyduty vehicle. Therefore, Dallas legislators are engaged to developed significant steps toward the implementation of high-speed rail (HSR) systems via Shinkansen N700 series trains. Yet for an effective implementation, there is need to develop a systematic process that accounts for all emissions generated over its lifetime. Life Cycle Assessment is one of the most used methods of evaluating the sources of pollution, reducing their impact and saving natural resources [2]. Therefore, it is of vital importance that such environmental analyses assume a complete life-cycle perspective including all process phase; a 'cradle-to-grave' approach that evaluates raw material extraction, manufacturing, transportation, construction, operation \& maintenance, and end-of-life of vehicle, infrastructure and fuel consumption to explicitly determine the overall and phase benefit of pollutants and energy use reduction.

The LCA process was developed using International Organization for Standardization (ISO) 14040, an approach that includes data acquisition for material and fuel consumption throughout the life of railway vehicle and infrastructure. However, since LCA process requires comprehensive and detailed information, that are not always available, this study make use of the private and well-established software (SimaPro) and database (Ecoinvent 3.3) considered to be one of the most used data program for LCA process. The assessed results from HSR system will then be compared with similar LCA results of highway and air modes to determine findings and suggestion improvements.

\section{Methodology}

This systematic process starts with the definition of goal and scope which outline the system objectives, its boundaries, and the functional unit, in Vehicles Kilometers Traveled (VKT). Input and output data collection for material, energy and emissions by each substance, were captured in the inventory analysis section, consistent with similar studies in U.S., Europe and Asia. The life cycle inventory is then calculated for environmental impact using Impact 2002+ methodology. Finally, results are interpreted and conclusion drawn for suggestions and improvement to the total life cycle process. Figure 1 bellow describes the life cycle assessment framework process, as per the environmental management and life cycle assessment standards.

\footnotetext{
* Corresponding author: rrkommalapati@pvamu.edu
} 


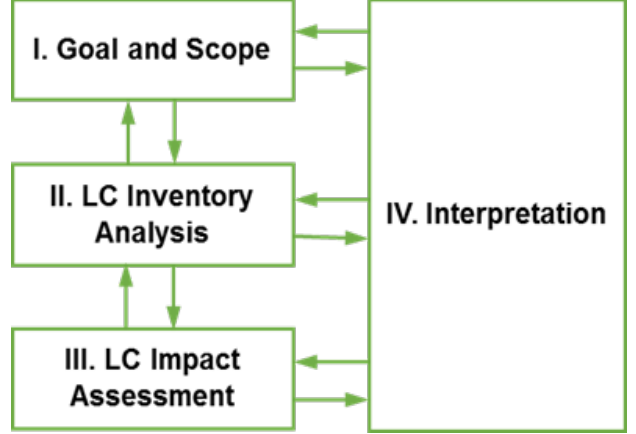

Fig. 1. Life cycle assessment framework.

The HSR system analysis was divided in three main sub-systems (vehicle, infrastructure and a combination of both), in which, each subsystem accounts for various phase life cycle processes including: raw material extraction and processing, vehicle manufacturing, material distribution, construction, operation \& maintenance and end-life. In addition, the system boundary also accounts for phase study of facilities and auxiliary equipment precisely, rail track, bridges, culvert, stations, and maintenance facilities along the I-45 corridor. Impact from electricity generation and fossil fuel products are not part of the assessment scope assuming that the project will use available electricity sources in the region. Figure 2 bellow shows the system boundary for both vehicle and infrastructure including the analyses of alternative transportation mode (Air and Road).

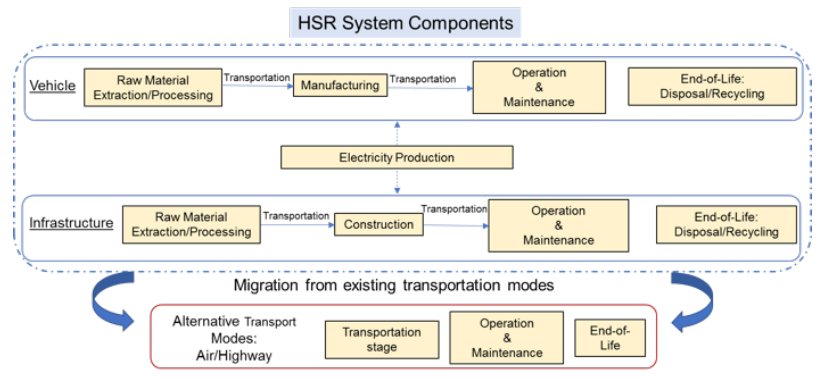

Fig. 2. System boundary and unit processes for LCA of the HSR system.

Total emissions of a given pollutant were calculated considering the HSR lifetime of 20 years in VKT year. Equation 1 expresses the individual system's emissions calculated for both mid and end point results; E: Emissions of a given pollutant in VKT/years; TE: Total life time emission of a given pollutant; $\mathrm{D}_{\mathrm{t}}$ : Total lifetime distance traveled (km/years).

$$
E(V K T)=\frac{T E_{i}}{D_{t}}
$$

The total distance traveled reflects the initial operating condition of the HSR System. Under this condition, the train is expected to depart every 30 minutes during pick-hours and hourly during the off peak, for a total of 18 hours of operations and 6 hours of system maintenance and inspection. This assumption results in an average of 68 trips per day and a total of 10108135.79 kilometers traveled a year. The model for road and air freight transportation, is implemented using an excel spreadsheet and existing data from similar studies. For the alterative transport module, the emission factors form others studies were summarized to calculate total environmental impact of air and highway mode, along the Dallas - Houston Corridor.

\subsection{Material extraction and processing}

The vehicle used in this study is the Shikansen 700 train, manufactured in Japan. However, due to lack of information on the Japan's vehicle inventory this assessment considers similar size train manufactured in German, which inventory is available in the ecoinvent 3.3 database, as per the approach used California and China $[3,4]$ study. Data for energy and material used for construction was retrieved from published report of Dallas -Houston HSR Environmental Impact Statement sponsored by the Department of Transportation and by the Texas Central Railroad (TCRR) engineers [5].

\subsection{Manufacturing/construction}

Initially the project will start with two vehicles of 8 cars and seating capacity of 400 passengers. Both vehicles are considered to be manufactured in Japan using the available energy in the region. Impute for vehicle manufacturing were primarily electricity and the processed aluminum, steel organic and non-organic material (glass, plastic and resign), which represents vehicle main material and the manufacturing module from SimaPro ${ }^{\circledR}$ software. Infrastructure material and energy used accounts for four years of construction period. The railway infrastructure includes rail track, bridges, culvert, stations, Trainset Maintenance Facilities (TMF) and Maintenance-of-Way (MOW) facilities.

\subsection{Transportation}

Material for track, stations and other support facilities will be purchased within the proximity of I-45 corridor and transported by diesel heavy pickup trucks. Other material such as rail, reinforcement steel, structural steel, and aggregate are transported to the site via the existing Houston rail system. On the other hand, the vehicle transportation is considered to be by boat from the Kinkisharyo manufacturing in Osaka, Japan to Galveston port via Panama Canal. Apart from material, this process also accounts for emissions per kilometers traveled, for passenger transportation.

\subsection{Operation and maintenance}

This phase was modeled considering all the energy and material required operating and maintaining the railway system at the initial phase. The end-to-end route distance was calculated to be approximately 239 miles operated by two trains at the speed of $205 \mathrm{rpm}$, as per the initial operating conditions. The total electricity consumption, 
for vehicle operation, is estimated to be $448.87 \mathrm{MWh}$ in addition to the $538.9 \mathrm{MWh}$, estimated for maintenance. Three stations of 60 acres each are projected along the Dallas - Houston corridor [5]. Other products such as lubricates, diesel, paint, water and metals are also accounted for yet, in a smaller scale.

\subsection{End-life}

The end-life assessment model was stablished considering the disposal and recycling mode of material and energy used throughout the life cycle phase. A small amount of vehicle material is used for recycling. Due to the variability on material used for vehicle manufacturing at the end-life, vehicles are scrapped and disposed. Infrastructure material which is part of stations and catenaries were mostly steel and aluminum, both with high percentage of recycling rate.

\section{RESULTS AND DISCUSSION}

This section outlines the life cycle emissions inventory of Dallas-Houston corridor HSR system in terms of $2002+$ methodology, midpoint categories selected based on defined boundaries and required inventory information established at the goal and scoping phase. The overall characterization assessment suggests that infrastructure, dominates the lifecycle process with more $80 \%$ of the total emissions, in all categories (Table 1). The significance in infrastructure emissions results echoes the amount of resources (cooper, concrete, steel, epoxy, rebar and others material) used during the four years period of track and facility construction. Vehicle emission are very small (almost insignificant) compared infrastructure and most of the high impacted areas are mining and material processing which reflects the high emissions values in aquatic and terrestrial ecotoxicity. These emissions impact all areas (air, water and soil) resulting in potential disappearance of species, species during a certain period. Moreover, the impact of nonrenewable energy (primary energy extracted) observes high values due to the fact that there are zero recycling in the infrastructure process. The Global Warming effect is mostly influenced by the fossil fuel use (natural gas, crude oil and coal), during the infrastructure construction, vehicle material processing and operation phase which is a consequence of the large volumes of diesel and gasoline used for the operation of equipment in addition to the contribution of electricity generation sources such as lignite and hard coal. As shown in Figure 1, fossil fuel contributes with 90 percent of the total used energy and $70 \%$ on the total infrastructure. The high amount of fossil fuel consumption directly impact the $\mathrm{CO}_{2}$ released to the atmosphere. The evidence of fossil fuel use is observed in the infrastructure and vehicle cumulative energy analyze. Transportation by heavy truck, in the construction phase, increases the demand of fossil fuel.
Table 1. Life cycle HSR system emissions by midpoint characterization (20-year operation).

\begin{tabular}{|c|c|c|c|c|}
\hline $\begin{array}{c}\text { Emissions } \\
\text { (VKT/year) }\end{array}$ & $\begin{array}{c}\begin{array}{c}\text { Unit } \\
\text { (millions) }\end{array} \\
\end{array}$ & Total & Vehicle & $\begin{array}{c}\begin{array}{c}\text { Infrastru } \\
\text { cture }\end{array} \\
\end{array}$ \\
\hline Carcinogens & $\mathrm{kg} \mathrm{C}_{2} \mathrm{H}_{3} \mathrm{Cl}_{\mathrm{eq}}$ & 600 & 7.09 & 593 \\
\hline $\begin{array}{c}\text { Non- } \\
\text { carcinogens }\end{array}$ & $\mathrm{kg} \mathrm{C}_{2} \mathrm{H}_{3} \mathrm{Cl}_{\mathrm{eq}}$ & 1026 & 11.28 & 1015 \\
\hline $\begin{array}{c}\text { Respiratory } \\
\text { inorganics }\end{array}$ & $\mathrm{kg} \mathrm{PM}_{2.5 \mathrm{eq}}$ & 142 & 8.26 & 133 \\
\hline $\begin{array}{l}\text { Ionizing } \\
\text { radiation } \\
\end{array}$ & Bq C-14 eq & 711072 & 36587 & 674485 \\
\hline $\begin{array}{c}\text { Ozone layer } \\
\text { depletion }\end{array}$ & $\mathrm{kg} \mathrm{CFC}-11_{\text {eq }}$ & $3.73 \mathrm{E}-03$ & $5.37 \mathrm{E}-05$ & $3.67 \mathrm{E}-03$ \\
\hline $\begin{array}{l}\text { Respiratory } \\
\text { organics }\end{array}$ & $\mathrm{kg} \mathrm{C}_{2} \mathrm{H}_{4 \mathrm{eq}}$ & 93.13 & 0.13 & 93.00 \\
\hline $\begin{array}{c}\text { Aquatic } \\
\text { ecotoxicity }\end{array}$ & kg TEG water & 3515678 & 78123 & 3437555 \\
\hline $\begin{array}{l}\text { Terrestrial } \\
\text { ecotoxicity }\end{array}$ & kg TEG soil & 1226840 & 18452 & 1208388 \\
\hline $\begin{array}{l}\text { Terrestrial } \\
\text { acid/nutri }\end{array}$ & $\mathrm{kg} \mathrm{SO}_{2 \mathrm{eq}}$ & 918 & 21.0 & 897 \\
\hline $\begin{array}{c}\text { Land } \\
\text { occupation }\end{array}$ & $\mathrm{m}^{2}$ org.arable & 2966 & 3.96 & 2962 \\
\hline $\begin{array}{c}\text { Aquatic } \\
\text { acidification }\end{array}$ & $\mathrm{kg} \mathrm{SO}_{2 \mathrm{eq}}$ & 293 & 7.33 & 285 \\
\hline $\begin{array}{c}\text { Aquatic } \\
\text { eutrophication }\end{array}$ & $\mathrm{kg} \mathrm{PO}_{4} \mathrm{P}$-lim & 26.2 & 1.00 & 25.2 \\
\hline Global warming & $\mathrm{kgCO} \mathrm{CO}_{2 \mathrm{q}}$ & 50438 & 1960 & 48478 \\
\hline $\begin{array}{c}\text { Non-renewable } \\
\text { energy }\end{array}$ & MJ & 674094 & 27437 & 646658 \\
\hline $\begin{array}{l}\text { Mineral } \\
\text { extraction }\end{array}$ & MJ & 8224 & 21 & 8203 \\
\hline
\end{tabular}
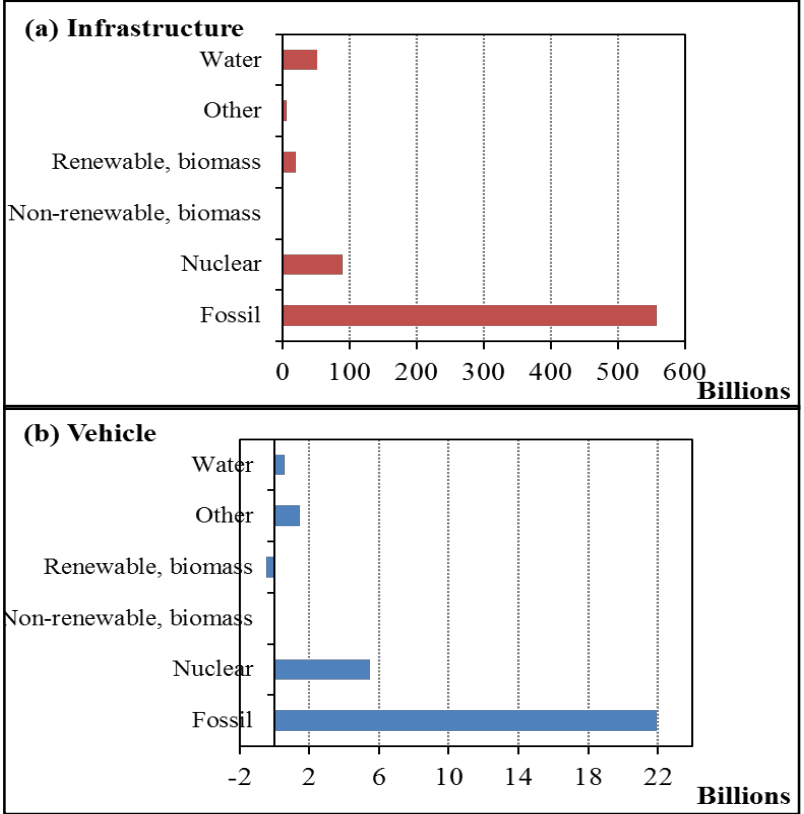

Fig. 3. Analysis of cumulative energy demand for (a) Infrastructure; and (b) vehicle.

Similar to the mid-point, the end-point results accounts are mostly allocated to the infrastructure, one more showing the effect of non-recyclable material. Figure 4 compares the significance of criteria air pollutants (CAP) and greenhouse gases (GHG) 
emissions in life cycle stages. Environmental emissions relatively to CAPs $\left(\mathrm{NO}_{x}, \mathrm{PM}, \mathrm{SO}_{2}\right.$, and $\left.\mathrm{O}_{3}\right)$ and GHGs $\left(\mathrm{CO}_{2}\right.$ fossil, and $\left.\mathrm{CH}_{4}\right)$ emissions for the railway system life cycle using 16 categories of impact 2002+ methodology. The characterization of infrastructure environmental results suggests that the operation phase is the most significant contributor with approximately $70-90 \%$ of all emission with exception for the ozone and carbon monoxide. As per the vehicles material it shows substantial impact, when compared with others lifecycle phases. Figure 5 describes the comparison of life cycle $\mathrm{CO}_{2}$ and $\mathrm{CO}$ emissions from the HSR system with Federici et al. (2008), who studies the LCA of Italian railway system [6]. The $\mathrm{CO}_{2}$ emissions for the Shinkansen N700 train are 50\% lower; however, CO emissions are significantly higher. This could be due to the nature of electricity sourcing used for the HSR system, having higher composition from natural gas and the infrastructure construction stage of the HSR system, which involves truck transportation of raw materials.
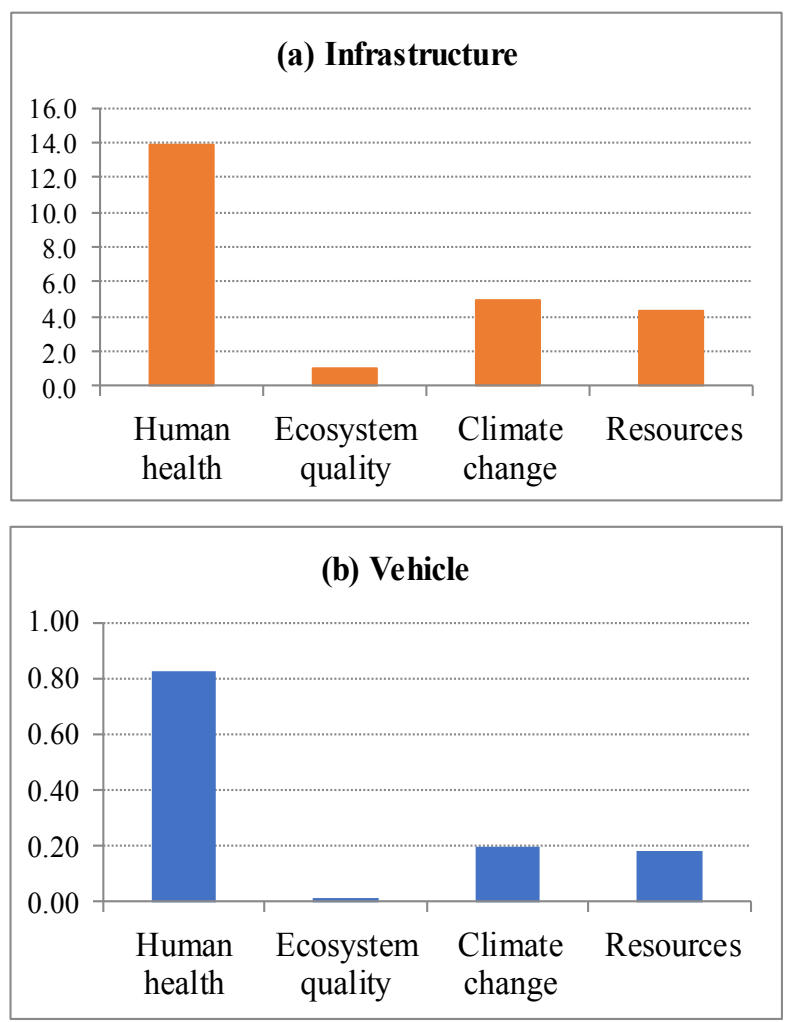

Fig. 4. Environmental Analysis of HSR at end-point.

\section{Conclusions}

This study conducted an environmental lifecycle assessment (LCA) of the HSR system in the I-45 corridor, using SimaPro $8.5^{\circledR}$ and the Ecoinvent 3.3 inventory database, and estimated the net change in environmental impacts across 14-midpoint and 4endpoint impact categories using Impact 2002+ life cycle impact assessment method. The system boundary for the LCA study covers two major components, (i) life cycle of infrastructure, which includes stages, raw material extraction, manufacturing, operation \& maintenance, and end-of-life, as well as transportation; (ii) complete life cycle of the N700 trains manufactured in Japan and transported to U.S. Results indicate that over the 20-year design life of the HSR system the total GHG emissions from the vehicle life-time would be $9.695 \mathrm{kgCO}_{2} \mathrm{eq} / \mathrm{VKT}$, out of which the fossil-fuel usage during vehicle operation is the primary contributor, accounting for $97 \%$ of the GHG emissions. For the infrastructure, total life-time GHG emissions would be $239 \mathrm{kgCO}_{2} \mathrm{eq} / \mathrm{VKT}$, out of which, $94 \%$ are from the construction stage. Infrastructure is the dominant contributor to end-point impacts in human health category, with $58 \%$ of total impact across all damage categories. Within human health category, PM2.5 is the major factor, and originate from fossil-fueled electricity generation and processing stage of construction materials. Preliminary comparison with other HSR systems in Italy indicates that the I-45 system would have $40 \%$ lower life cycle $\mathrm{CO}_{2}$ emissions.

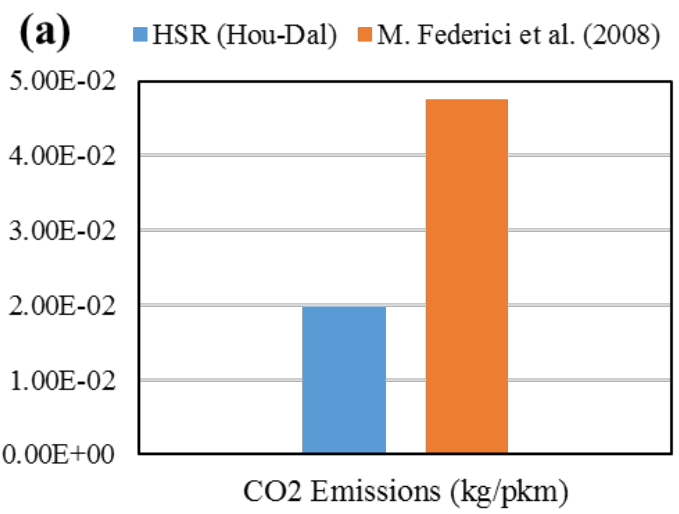

(b) $\quad$ HSR (Hou-Dal) $\square$ M. Federici et al. (2008)

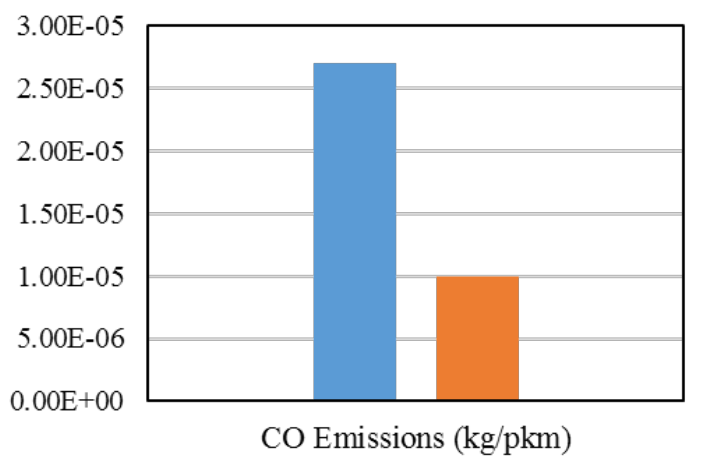

Fig. 5. Comparison of I-45 HSR emissions with Italian Railway System, (a) $\mathrm{CO}_{2}$; (b) $\mathrm{CO}$ emissions.

\section{References}

1. U.S. Energy Information Administration. (2018). Energy-Related Carbon Dioxide Emissions by State, 2000-2015, (January), 2000-2015.

2. Y. Kikuchi. (2016). Life Cycle Assessment, Plant Factory, (6), 321-329. doi: 10.1016/B978-0-12801775-3.00024-X.

3. M. Chester, and A. Horvath. (2010). Life-cycle assessment of high-speed rail: The case of California, Environmental Research Letters, 5(1). doi: 10.1088/1748-9326/5/1/014003. 
4. Y. Yue, et al. (2015). Life cycle assessment of High Speed Rail in China, Transportation Research Part D: Transport and Environment. Elsevier Ltd, 41, 367-376. doi: $10.1016 /$ j.trd.2015.10.005.

5. C. Sepulveda (2015) Appendix E: Dallas to Houston High-Speed Rail Draft Environmental Impact Statement, AECOM. doi: 10.1016/B978-0-08-0919065.00027-6.

6. M. Federici, et al. (2008). A thermodynamic, environmental and material flow analysis of the Italian highway and railway transport systems, Energy, 33(5). 760-775.

doi: https://doi.org/10.1016/j.energy.2008.01.010. 